\title{
Quantitative sampling and analysis of trace elements in atmospheric aerosols: impactor characterization and Synchrotron-XRF mass calibration
}

\author{
A. Richard ${ }^{1}$, N. Bukowiecki ${ }^{1}$, P. Lienemann ${ }^{2}$, M. Furger ${ }^{1}$, M. Fierz ${ }^{3}$, M. C. Minguillón ${ }^{4}$, B. Weideli ${ }^{2}$, R. Figi ${ }^{5}$, \\ U. Flechsig ${ }^{6}$, K. Appel ${ }^{7}$, A. S. H. Prévôt ${ }^{1}$, and U. Baltensperger ${ }^{1}$ \\ ${ }^{1}$ Laboratory of Atmospheric Chemistry, Paul Scherrer Institut, Villigen, Switzerland \\ ${ }^{2}$ School of Life Sciences and Facility Management, Wädenswil, Switzerland \\ ${ }^{3}$ University of Applied Sciences Northwestern Switzerland, Windisch, Switzerland \\ ${ }^{4}$ Institute for Environmental Assessment and Water Research (IDAEA), CSIC, Barcelona, Spain \\ ${ }^{5}$ Empa, Swiss Federal Laboratories for Materials Testing and Research, Dübendorf, Switzerland \\ ${ }^{6}$ Swiss Light Source, Paul Scherrer Institut, Villigen, Switzerland \\ ${ }^{7}$ Hamburger Synchrotronstrahlungslabor at Deutsches Elektronen-Synchrotron DESY, a Research Centre of the Helmholtz \\ Association, Hamburg, Germany
}

Received: 16 April 2010 - Published in Atmos. Meas. Tech. Discuss.: 1 June 2010

Revised: 27 August 2010 - Accepted: 6 October 2010 - Published: 20 October 2010

\begin{abstract}
Identification of trace elements in ambient air can add substantial information to pollution source apportionment studies, although they do not contribute significantly to emissions in terms of mass. A method for quantitative size and time-resolved trace element evaluation in ambient aerosols with a rotating drum impactor and synchrotron radiation based X-ray fluorescence is presented. The impactor collection efficiency curves and size segregation characteristics were investigated in an experiment with oil and salt particles. Cutoff diameters were determined through the ratio of size distributions measured with two particle sizers. Furthermore, an external calibration technique to empirically link fluorescence intensities to ambient concentrations was developed. Solutions of elemental standards were applied with an ink-jet printer on thin films and area concentrations were subsequently evaluated with external wet chemical methods. These customized and reusable reference standards enable quantification of different data sets analyzed under varying experimental conditions.
\end{abstract}

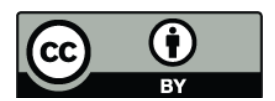

Correspondence to: M. Furger (markus.furger@psi.ch)

\section{Introduction}

Information on temporal variation and size segregation of trace elements in ambient air greatly facilitates the identification of pollution sources. Particulate matter (PM) emissions caused by traffic exhaust and combustion processes are predominant in the fine size range (particle diameter $<1 \mu \mathrm{m}$ ). In contrast, mechanically produced particles and mineral or resuspended road dust particles are mainly found in the coarse size fraction (particle diameter $>1 \mu \mathrm{m}$ ). Most emissions such as traffic and industry related emissions or atmospheric dilution processes vary within a few hours. Conventional 24-h filter measurements do not detect these rapid changes due to the missing time resolution. Therefore, cascade impactors with shorter measurement intervals (in the order of hours) as developed by Lundgren (1967) are very valuable in combining size segregation with high time resolution. A variety of impactors with different size cuts, number of impaction stages, number of nozzles and substrates for various analysis methods exist (Hering, 1979; Raabe et al., 1988; Berner et al., 1980; D'Alessandro et al., 2003; Marple et al., 1991; Marple, 2004). Cahill et al. (1985) and Cliff et al. (2003) designed a three-stage rotating drum impactor. Bukowiecki et al. (2005) presented a modified design to obtain particle cutoff sizes of $2.5 \mu \mathrm{m}, 1 \mu \mathrm{m}$, and approximately $0.1 \mu \mathrm{m}$. They included a first characterization of the impactor

Published by Copernicus Publications on behalf of the European Geosciences Union. 
by determining the collection efficiency curves. The highly time resolved measurements of trace elements in ambient air result in low amounts of sample material in the range of a few $\mu$ g per analyzed area. This demands a highly sensitive detection method such as synchrotron radiation based X-ray fluorescence spectrometry (SR-XRF), which provides a high sensitivity on small analysis areas. Bukowiecki et al. (2008) established an automated procedure to analyze many spectra in a reasonable time.

Since deviations relative to the desired size cuts would result in an incorrect size attribution of the particulate matter, knowledge about the size segregation characteristics of the impactor is crucial for the data quality. This paper describes the determination of the inverse collection efficiency curves for the three size ranges by the use of an artificial aerosol generator. The rotating drum impactor is introduced in Sect. 2.1, followed by the results of the characterization study in Sect. 2.2. Trace elements sampled with the described impactor were analyzed with SR-XRF (see Sect. 3.1). For a quantitative analysis, raw spectral count rates have to be linked to ambient concentrations. The production of adequate reference standards for a consistent elemental mass calibration under different experimental conditions is the main focus of this paper, discussed in Sects. 3.2 and 3.3. Mass calibrated time resolved and size-segregated impactor data were finally compared to 24-h filter data in Sect. 4.

\section{Sampling method}

\subsection{Impactor characterization}

The rotating drum impactor (RDI; Bukowiecki et al., 2005, 2009) is a modification of the 3-stage UC Davis Rotating Drum Unit for Monitoring (3DRUM; Cahill et al., 1985). The 3DRUM was designed for continuous sampling of ambient aerosols in three size ranges of aerodynamic diameter: $2.5-1.15 \mu \mathrm{m}, 1.15-0.34 \mu \mathrm{m}$, and 0.34 to approximately $0.1 \mu \mathrm{m}$ with a sample flow of $22.71 \mathrm{~min}^{-1}$. The objective of the modification was to design a new impactor with step-wise rotation for a volumetric flow of $16.61 \mathrm{~min}^{-1}$ (corresponding to $1 \mathrm{~m}^{3} \mathrm{~h}^{-1}$ ) and particle size segregation in ranges of $10-$ $2.5 \mu \mathrm{m}, 2.5-1 \mu \mathrm{m}$, and 1 to approximately $0.1 \mu \mathrm{m}$. The three impactor stages will be referred to as stage $10\left(\mathrm{PM}_{10-2.5}\right)$, stage $2.5\left(\mathrm{PM}_{2.5-1}\right)$ and stage $1\left(\mathrm{PM}_{1-0.1}\right)$ in the following. Particulate matter $\geq 10 \mu \mathrm{m}$ is removed by the $\mathrm{PM}_{10^{-}}$ inlet (Digitel AG, DPM10/2,3/01) on top of the instrument. Due to the stepwise movement of the drum, aerosol particles are deposited in a bar-code-like structure on the film, as illustrated in Fig. 1. Modified RDI drums were designed to be used for sampling as well as for subsequent SR-XRF analysis, see Bukowiecki et al. (2008) and Sect. 3.1. These notched aluminum wheels allow the beam to pass through the wheels without interaction with metallic wheel material. They are covered with a $6-\mu \mathrm{m}$ polypropylene (PP) film

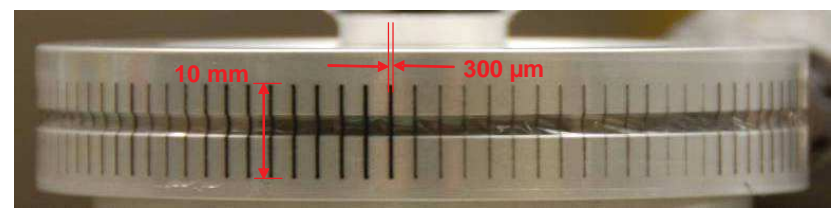

Fig. 1. RDI sampling drum: a notched aluminum wheel, coated with a $6-\mu \mathrm{m}$ PP film, used for sampling and subsequent SR-XRFanalysis as well as for the calibration. The bar code-like structure of deposited particulate matter is visible on the film. The black color on the depicted stage 1 bars with a width of $300 \mu \mathrm{m}$ and a height of $10 \mathrm{~mm}$ is mainly caused by soot deposition.

coated with Apiezon M (M \& I Materials Ltd.), a siliconfree hydrocarbon grease, to reduce sampling losses due to bouncing effects. One wheel has a capacity for 96 sample bars. An advantage of the combination of RDI sampling on customized wheels with subsequent SR-XRF analysis is that measurements can take place without further sample treatment, unlike most conventional techniques such as inductively coupled plasma optical emission spectrometry (ICPOES) and mass spectrometry (ICP-MS), reducing the risks of contamination and loss of analyte.

The impaction parameter, or Stokes number, is defined for an impactor as the ratio of the particle stopping distance at the average nozzle exit velocity $U$ and the nozzle half-width, $D_{j} / 2$ :

$\operatorname{Stk}_{50}=\frac{\tau U}{D_{j} / 2}=\frac{\rho_{p} d_{50}^{2} U C_{\mathrm{c}}\left(d_{50}\right)}{9 \eta D_{j}}$

with $\tau$ being the relaxation time, $\rho_{p}$ the particle density, $d_{50}$ the cutoff diameter, $C_{\mathrm{c}}$ the Cunningham-slip correction factor and $\eta$ the viscosity of air. Under the assumption that the Stokes number remains the same for a given impactor design, the nozzle dimensions for the new RDI were derived through Eq. (1): first, Stokes numbers were calculated for the setup of the original 3DRUM. Based on this, the dimensions for the rectangular nozzles of the RDI with new cutoff sizes were determined accordingly as $(1.52 \times 10) \mathrm{mm},(0.68 \times 10) \mathrm{mm}$ and $(0.3 \times 10) \mathrm{mm}$, see Table 1 for details. Since the cutoff diameter $d_{50}$ of the lowest stage of the 3DRUM is not known precisely, it was estimated to lie in the range between 0.06 and $0.12 \mu \mathrm{m}$. Due to this uncertainty, the $d_{50}$ of the RDI for the lowest stage is expected to lie between 0.1 and $0.2 \mu \mathrm{m}$.

Hinds (1982) suggested an ideal Stokes number of $\mathrm{Stk}_{50}=0.59$ for $50 \%$ collection efficiency for impactors with rectangular nozzles. To obtain a similar Stokes number for stage 1 as well, either a pressure of approximately $10 \mathrm{kPa}$ and with this an unrealistically high jet-velocity would be necessary, which could provoke significant particle bouncing. Alternatively, the nozzle size would have to be reduced to $\leq 0.1 \mathrm{~mm}$ for an operation of the impactor at realistic pressure conditions (around $80 \mathrm{kPa}$ ). Small-sized nozzles were not practical because of the risk of blockage when the 
Table 1. Values of characteristic parameters of 3DRUM and RDI as well as penetration midpoint diameters in $\mu \mathrm{m}$ (aerodynamic diameter) calculated from the second derivative $E^{\prime \prime}\left(d_{\mathrm{p}}\right)$ of the sigmoidal fit for RDI stages 10, 2.5, and 1. The free parameter $c_{i}$ of the sigmoidal fit, which is an equivalent way to obtain the inflection point, is listed as well.

\begin{tabular}{lccc}
\hline & stage 10 & stage 2.5 & stage 1 \\
\hline 3DRUM $d_{50}[\mu \mathrm{m}]$ & 1.1 & 0.34 & $0.06-0.12$ \\
3DRUM $D_{j}[\mathrm{~mm}]$ & 0.82 & 0.31 & 0.25 \\
Stk $50(3 \mathrm{DRUM}, \mathrm{RDI})$ & 0.49 & 0.44 & $0.06-0.14$ \\
RDI $d_{50}[\mu \mathrm{m}]$ & 2.5 & 1.0 & $0.1-0.2$ \\
RDI $D_{j}[\mathrm{~mm}]$ & 1.52 & 0.68 & 0.3 \\
$d_{\mathrm{p}}$ from $E^{\prime \prime}\left(d_{\mathrm{p}}\right)$ fit & $2.4 \pm 0.2$ & $1.03 \pm 0.02$ & $0.20 \pm 0.02$ \\
$d_{\mathrm{p}}$ from $c_{i}$ & $2.4 \pm 0.2$ & $1.03 \pm 0.02$ & $0.20 \pm 0.02$ \\
\hline
\end{tabular}

instrument was employed in longer field campaigns. Moreover, the use of multiple small-area nozzles per impactor stage to achieve a more ideal Stokes number under low pressure conditions (as e.g. used in the electrical low-pressure impactor - ELPI, Marjamäki et al., 2000) was not favorable, as the small deposition areas would add additional uncertainty to the applied analysis which produces the best results for large and homogeneous deposition areas. Thus, the low Stokes number for stage $1(0.06-0.14)$ is a result of the constraints of the coupled sampling and analysis method considered here at the expense of a reduced impaction efficiency.

\subsection{Determination of cutoff sizes}

RDI characterization studies were previously conducted using laboratory room air as a quasi-stable proxy for urban ambient air (Bukowiecki et al., 2009). This experimental approach was suitable for the scope of that study, but the necessary corrections through the use of room air restrict a general application. For this study, the cutoff diameters for stages 10 and 2.5 were determined through application of a condensation monodisperse aerosol generator (CMAG, TSI Inc., Model 3475), as in Kwon et al. (2003), and an aerodynamic particle sizer (APS, TSI Inc., Model 3321). Particles produced by the $\mathrm{CMAG}$ were quasi-monodisperse dioctyl sebacate (DEHS, $\mathrm{C}_{26} \mathrm{H}_{50} \mathrm{O}_{4}$ ) droplets in the size range from approx. 0.3 to $5 \mu \mathrm{m}$ (geometric standard deviation $\sigma_{g}=1.4$ ). Settings for the CMAG varied within the following values: saturator flow $2.25-31 \mathrm{~min}^{-1}$, saturator temperature $235-240{ }^{\circ} \mathrm{C}$, while the reheater temperature remained constant at $100^{\circ} \mathrm{C}$. Average particle concentration produced by the CMAG was 400 particles $\mathrm{cm}^{-3}$ after a dilution stage avoiding a too high concentration in the APS. For the cutoff determination of stage 1, particles in the order of $0.1 \mu \mathrm{m}$ were required, which are difficult to produce with the CMAG. For this purpose, polydisperse $\mathrm{NaCl}$ particles

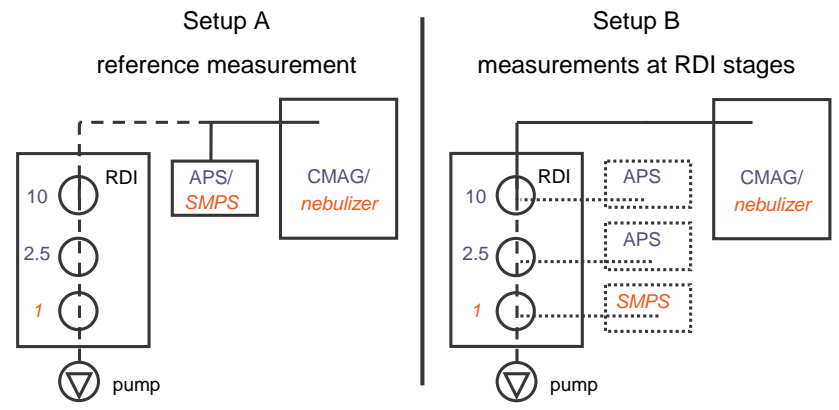

Fig. 2. Schematic layout of the two subsequent setups for cutoff determination experiments: the left side illustrates the reference measurement (setup A), where the concentration of oil droplets produced by the CMAG is measured directly with the APS. For stage 1 the $\mathrm{NaCl}$ concentration produced by a nebulizer is measured with the SMPS. The RDI is connected in order to simulate realistic flow conditions. The right side displays the actual experimental setup, where the APS is connected subsequently to the covers of stages 10 and 2.5 and then the SMPS is connected to the cover of stage 1 (setup B).

were produced with a nebulizer, directed through a dryer and measured with a scanning mobility particle sizer (SMPS) consisting of a differential mobility analyzer (DMA, TSI Inc., Model 3081) and a condensation particle counter (CPC, TSI Inc., Model 3025, high flow). However, higher particle bouncing is expected for $\mathrm{NaCl}$ particles because they do not stick as well to the substrate as the oil droplets.

While the APS is a suitable device to measure coarse particles (APS size interval: 0.542-19.8 $\mu \mathrm{m}$, aerodynamic diameter), the SMPS is a more adequate choice to sample particles in the fine fraction (size interval of employed SMPS: 7-300 nm, mobility diameter). The mobility diameter $d_{\text {mob }}$ measured with the SMPS was transformed into an aerodynamic diameter $d_{\mathrm{p}}$ using the following recursive equation:

$d_{\mathrm{p}}=d_{\mathrm{mob}} \sqrt{C_{\mathrm{c}}\left(d_{\mathrm{mob}}\right) / C_{\mathrm{c}}\left(d_{\mathrm{p}}\right)} \sqrt{\rho_{p} / \rho_{0}}$

taking into account the respective Cunningham-slipcorrection factors $C_{\mathrm{c}}\left(d_{\mathrm{p}}\right)$ and $C_{\mathrm{c}}\left(d_{\mathrm{mob}}\right)$, the density of air $\rho_{0}$ and the density of DEHS $\left(\rho_{p}=0.91 \mathrm{~g} \mathrm{~cm}^{-3}\right)$ and $\mathrm{NaCl}$ particles $\left(\rho_{p}=2.16 \mathrm{~g} \mathrm{~cm}^{-3}\right)$, respectively.

Figure 2 displays the schematic experimental setup, which is essentially the same as in Bukowiecki et al. (2009). For the average particle concentration (reference measurement) the APS measured directly after the CMAG (subsequently referred to as setup A). In setup B, the APS measured the particle size distribution in a sequential manner after stages 10 or 2.5 and then the SMPS measured after stage 1. Switching the APS and SMPS back and forth from setup A to setup B eliminated differences previously encountered by using two different APS instruments (both APS Model 3321). Measurements in each setup were repeated at least 6 times, where a single measurement lasted for about $600 \mathrm{~s}$. Time intervals 

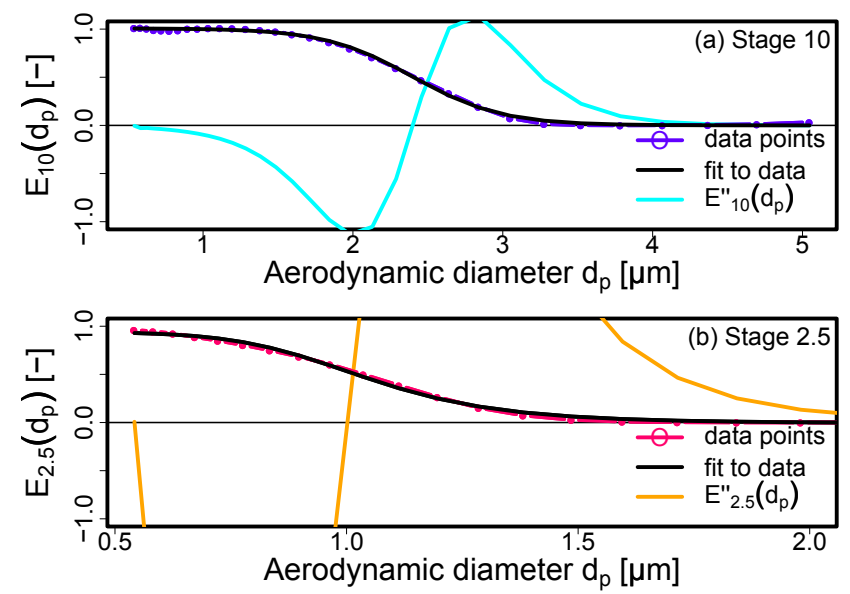

Fig. 3. Stage penetration curve $E_{i}\left(d_{\mathrm{p}}\right)$ for stages 10 and 2.5: ratio of size distributions obtained in setup B versus size distributions obtained in setup A. The upper panel (a) shows the ratio for stage 10, a sigmoidal fit was applied to data points. The second derivative $E_{i}^{\prime \prime}\left(d_{\mathrm{p}}\right)$ is shown on the same axis scale. The lower panel (b) shows data points and sigmoidal fit for stage $2.5, E_{2.5}^{\prime \prime}\left(d_{\mathrm{p}}\right)$ is shown on the same axis scale.

were $5 \mathrm{~s}$ for each APS sample and the SMPS scanning interval lasted about $300 \mathrm{~s}$.

Instruments were connected with conductive tubing (TSI Inc.) and attached to specially manufactured RDI stage covers. Experiments were performed at ambient temperature $\left(\approx 25^{\circ} \mathrm{C}\right)$. The flow was measured with a primary flow calibrator (A. P. Buck Inc.) and regulated with a mass flow controller (red-y, Vögtlin Ltd.) before each experiment to assure the necessary flow and pressure conditions for a correct operation of the RDI (i.e. $16.61 \mathrm{~min}^{-1}$ ). This is especially important for stage 1 because of the low cutoff diameter $(0.1-$ $0.2 \mu \mathrm{m})$. Here, the jet velocity is much higher $\left(106 \mathrm{~m} \mathrm{~s}^{-1}\right.$ compared to $18 \mathrm{~m} \mathrm{~s}^{-1}$, stage 10 , and $42 \mathrm{~m} \mathrm{~s}^{-1}$, stage 2.5 ) and the pressure drops from about 101 to $88 \mathrm{kPa}$. Stage 1 is close to the transition from an impaction to a diffusion controlled deposition regime. To ensure that identical pressure and flow conditions are maintained at the respective nozzles in both setups, inlet flow rate and pressure were monitored and adjusted accordingly. In order to accommodate for the additional flow rates when the particle sizers are connected to setup B (5 and $11 \mathrm{~min}^{-1}$ for the APS and SMPS, respectively), the RDI was connected also in setup A.

Size separation characteristics were obtained from collection efficiency curves plotted versus aerodynamic diameter. The cutoff diameter and the stage penetration midpoint diameter $d_{50}$ both imply the diameter where $50 \%$ of particles are collected and 50\% pass through (Hinds, 1982). Inverse efficiency curves $E_{i}\left(d_{\mathrm{p}}\right)$ were computed based on the ratio of the averaged particle size counts measured in setup B and setup A:
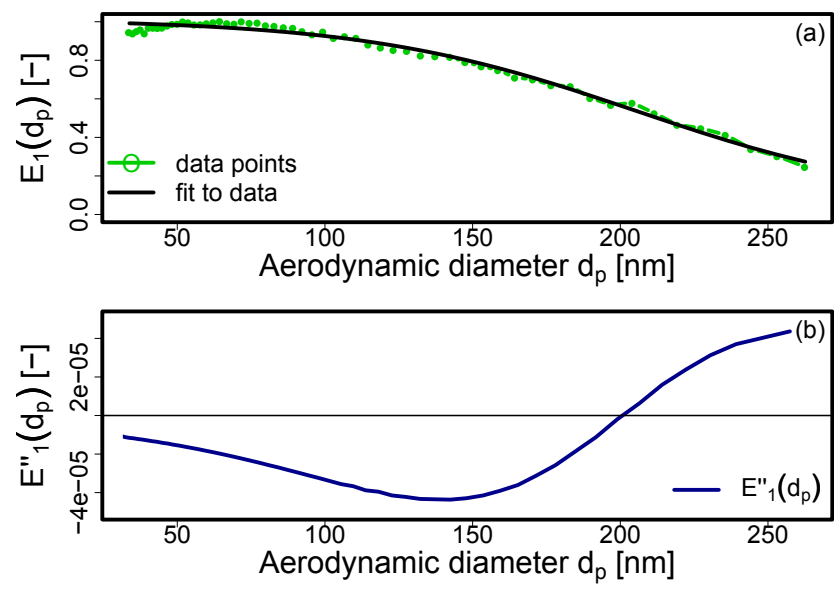

Fig. 4. Stage penetration curve $E_{1}\left(d_{\mathrm{p}}\right)$ for stage 1: ratio of size distributions obtained with the SMPS connected to the RDI (setup B) versus size distributions obtained with the SMPS connected to the nebulizer (setup A). The upper panel (a) shows the data points and the sigmoidal fit. For better readability the second derivative $E_{1}^{\prime \prime}\left(d_{\mathrm{p}}\right)$ is displayed in the lower panel (b).

$E_{i}\left(d_{\mathrm{p}}\right)=\frac{\text { counts }_{\text {setup } \mathrm{B}_{i}}}{\text { counts }_{\text {setup A }}}$

with $i$ being either stages 10, 2.5 or 1 . Following the concept introduced previously by Bukowiecki et al. (2009), $E_{i}\left(d_{\mathrm{p}}\right)$ is also referred to as stage penetration at a given particle size $d_{\mathrm{p}}$, i.e. the non-deposited particle fraction. Kwon et al. (2003) suggested a sigmoidal fit for the inverse efficiency curve:

$E_{i}\left(d_{\mathrm{p}}\right)=\frac{a_{i}}{1+\exp \left(\frac{-\left(d_{\mathrm{p}}-c_{i}\right)}{b_{i}}\right)}$

with parameters $a_{i}, b_{i}, c_{i}$, tuned to provide the best fit to the experimental data. In this approach the $d_{50, i}$ are obtained directly by the parameter $c_{i}$, the inflection point. This is equivalent to calculating the inflection point as zero point of the second derivative $E_{i}^{\prime \prime}\left(d_{\mathrm{p}}\right)$. All calculated cutoff diameters are compiled in Table 1 . Stage penetration curves $E_{i}\left(d_{\mathrm{p}}\right)$ and second derivatives $E_{i}^{\prime \prime}\left(d_{\mathrm{p}}\right)$ of the sigmoidal fits are displayed in Figs. 3 and 4. Already with little noise in the data pronounced peaks occur in the derivative, thus the concept is only applicable for the parts of the curve with very little noise. The fit in the region of diameters smaller than $100 \mathrm{~nm}$ for stage 1 is not as satisfactory as for the other stages because variations in the size distribution in the Aitken mode (particles $<100 \mathrm{~nm}$ ) can have considerable effects on the ratio.

If all particles larger than the cutoff diameter were impacted and all smaller particles passed through, the impactor would have perfectly sharp size cuts and a stepfunction efficiency curve. Deviations from this ideal theoretical step-function result in a number of oversized particles 
that pass through and a number of undersized particles that are collected, quantities which ideally should be symmetric. Bukowiecki et al. (2009) introduced the first derivative of $E_{i}\left(d_{\mathrm{p}}\right)$ as a measure for the cutoff sharpness, which is plotted in Fig. 5 versus the normalized diameter $d_{\mathrm{p}} / d_{50, i}$. For better readability all first derivatives $E_{i}^{\prime}\left(d_{\mathrm{p}}\right)$ were normalized to 1 . The curves suggest that the cutoff sharpness achieved with the tested RDI is rather broad, especially for stage 1, which was already observed by Bukowiecki et al. (2009). An implication is that the size limits of individual RDI stages might be slightly smeared out and that smaller particles could be deposited on a higher stage and vice-versa. Several comparisons to concentrations of 24-h filters obtained with highvolume samplers for $\mathrm{PM}_{10}, \mathrm{PM}_{2.5}$ and $\mathrm{PM}_{1}$ showed that this effect is not significant on a mass base, see also Sects. 4 and Bukowiecki et al. (2005). The values derived for the cutoff diameters of stage $10(2.4 \pm 0.2 \mu \mathrm{m})$ and stage 2.5 $(1.03 \pm 0.02 \mu \mathrm{m})$ correspond well with the theoretical values 2.5 and $1.0 \mu \mathrm{m}$, respectively. They confirm the values obtained in the previous study: $2.4 \pm 0.2 \mu \mathrm{m}$ and $1.0 \pm 0.02 \mu \mathrm{m}$. For stage 1 a value of $0.20 \pm 0.02 \mu \mathrm{m}$ was found, which lies within the expected range of $0.1-0.2 \mu \mathrm{m}$.

Through the use of two aerosol generators, the respective aerosol concentrations were high enough to obtain cutoff diameters directly from the data without any further corrections. The presented results verify a correct size segregation within the RDI.

\section{Technique for mass calibration}

\subsection{Synchrotron radiation based X-ray fluorescence spectrometry (SR-XRF)}

The low aerosol mass on individual RDI bars demands a highly sensitive detection method. Additionally, a method for a high-throughput analysis was required for RDI sampling in field campaigns, where the typical number of individual samples can easily reach about 5000. SR-XRF provides a sufficiently high sensitivity and easy sample handling, but it depends on many parameters and therefore requires external calibration in case not all of them are known (Rousseau et al., 1996). Calibration through model calculations of mass absorption coefficients, excitation factors and instrumental characteristics (fundamental parameter analysis) was not applicable due to the high variability in the elemental composition of sampled particles. Today adequate reference materials in terms of similar elemental composition, particle size, sample homogeneity and substrate thickness for ambient aerosol analysis on PP films are still scarce. Thus a general, reusable reference, similar to the sample in terms of matrix composition and sample thickness for calibration of each experimental setup and session was developed to obtain a correct quantification. This provides comparability between different analyses since conditions during

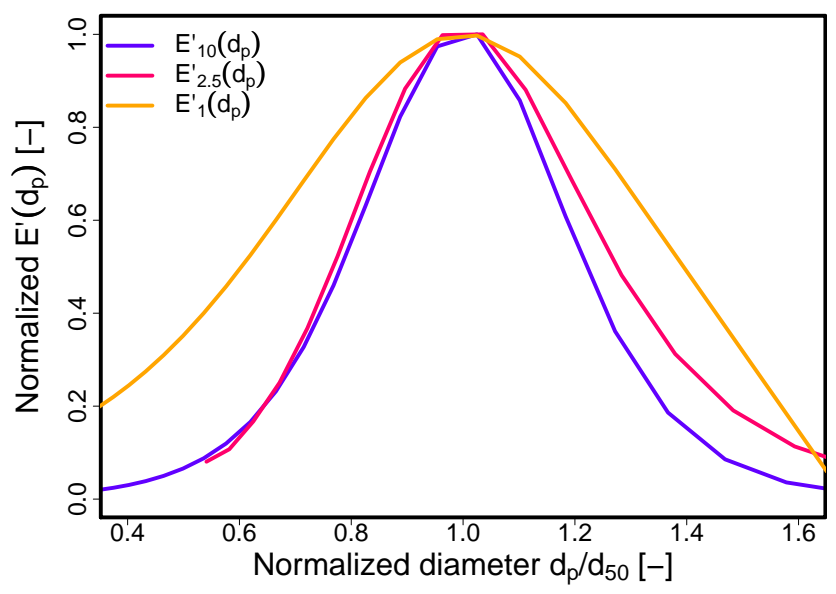

Fig. 5. Experimental RDI cutoff sharpness: normalized first derivatives of $E_{i}\left(d_{\mathrm{p}}\right)\left(E_{i}^{\prime}\left(d_{\mathrm{p}}\right)_{\max }=1\right)$ for all RDI stages 10, 2.5 and 1 plotted versus the normalized diameter $d_{\mathrm{p}} / d_{50, i}$. The $E_{i}^{\prime}\left(d_{\mathrm{p}}\right)$ curves represent a measure for the size-segregation sharpness in the RDI.

experimental sessions at different synchrotron radiation facilities, such as excitation energy, photon flux and detector efficiency can change significantly. This section explains the basic aspects of the applied SR-XRF setup, followed by a description of the development of a technique for external and internal reference element quantification (Sects. 3.2 and 3.3).

$\mathrm{K} \alpha$ lines of a wide range of elements (Al, Si, P, S, Cl, K, $\mathrm{Ca}, \mathrm{Ti}, \mathrm{V}, \mathrm{Cr}, \mathrm{Mn}, \mathrm{Fe}, \mathrm{Co}, \mathrm{Ni}, \mathrm{Cu}, \mathrm{Zn}, \mathrm{Rb}, \mathrm{Sr}, \mathrm{Zr}, \mathrm{Mo}, \mathrm{Cd}, \mathrm{Sn}$, $\mathrm{Sb}$ and $\mathrm{Ba}$ ) as well as the $\mathrm{L} \alpha$ line of $\mathrm{Pb}$ were detected with $\mathrm{XRF}$ at two synchrotron facilities. Elements with atomic number $Z=13-24$ (Al-Cr) were measured with a silicon drift detector (Roentec Xflash 2001 type 1102, Bruker AXS) with a nominal resolution of $155 \mathrm{eV}(\mathrm{Mn} \mathrm{K} \alpha$ at $5.9 \mathrm{keV})$ at the X05DA beamline in the Swiss Light Source (SLS) at the Paul Scherrer Institute, Switzerland. Total available photon energy ranges from 5.5 to $22.5 \mathrm{keV}$ at a bending magnet with a cryogenically cooled $\mathrm{Si}(111)$ channel cut monochromator (Flechsig et al., 2009). Trace elements were examined in the focused monochromatic mode, with an energy of $11.5 \mathrm{keV}$ and usable photon flux of $2 \times 10^{11}$ photons s$^{-1}$ within a $70 \times 140 \mu \mathrm{m}(h \times v$ full width of half maximum, FWHM) focus area. A helium atmosphere was applied to reduce absorption effects in air and to eliminate the Ar fluorescence line at $2.9 \mathrm{keV}$ (occurring with measurements in air). Elements with atomic number $Z=25-82(\mathrm{Mn}-\mathrm{Pb})$ were measured at the beamline L, HASYLAB, DORIS III storage ring at DESY where a bending magnet provides a polychromatic spectrum with usable photon statistics up to $80 \mathrm{keV}$. $\mathrm{Al}$ and $\mathrm{Cu}$ absorbers of various thicknesses (high-pass filter) can be used to shift the energy maximum towards higher energies and thus reducing background effects from lower energies. For measurements of the data set presented in Sect. 4 an 8 -mm Al absorber was used. A polychromatic $100 \times 200 \mu \mathrm{m}$ 
$(h \times v)$ wide beam irradiated the sample and a nitrogen cooled $\mathrm{Si}(\mathrm{Li})$-detector (Sirius 80, Gresham) with a nominal resolution of $144 \mathrm{eV}(\mathrm{Mn} \mathrm{K} \alpha)$ measured the fluorescence counts. This detector is suitable to measure $\mathrm{K} \alpha$ lines of heavier elements (up to the $\mathrm{Ba} \mathrm{K} \alpha$ line at $32 \mathrm{keV}$ ) due to the large active volume (Si crystal depth: $4 \mathrm{~mm}$, area: $80 \mathrm{~mm}^{2}$ ) and a Be window thickness of $12.5 \mu \mathrm{m}$. Since the detection efficiency of $\mathrm{Si}(\mathrm{Li})$ detectors decreases for lighter elements as electronic noise increases, a Si drift detector with a 3- $\mu$ m polymer window (plus a $0.5-\mu \mathrm{m}$ aluminum layer) and smaller active volume (depth: $450 \mu \mathrm{m}$, area: $10 \mathrm{~mm}^{2}$ ) with the ability to process higher count rates was employed for measurements at the SLS. Low peaking times (in the order of $\tau_{p}=1 \mu \mathrm{s}$ ) are suitable for this detector, but would lead to a too low energy resolution in the $\mathrm{Si}(\mathrm{Li})$ detector, which was operated with $\tau_{p}=12 \mu \mathrm{s}$. The efficiency of Si drift detectors decreases rapidly for higher energies because the thin Si crystal absorbs less than $30 \%$ above $11 \mathrm{keV}$. Thus, each detector is matched to the chosen excitation energies. The detector dead time was kept below $30 \%$ by reducing the size of the photon beam. Output and input count rates (OCR, ICR) were measured while varying the opening of exit slits to investigate the detector saturation regime. Determining the relationship between OCR and ICR for a given detector at given experimental conditions enabled correcting for potential dead time effects in the detector.

Sample wheels were rotated with a goniometer in steps of $3.51^{\circ}$, corresponding to the separation of individual RDI bars, and each bar was irradiated typically for 20-30 s. Since synchrotron radiation is linearly polarized, positioning the fluorescence detector in the polarization plane at an angle of $90^{\circ}$ with respect to the incident beam reduced the spectral background due to coherent and incoherent scattering substantially.

\subsection{Absolute mass calibration}

Fluorescence counts of sample elements can be linked to the area concentration $\left(\mu \mathrm{g} \mathrm{cm}^{-2}\right)$ if the deposited mass of one sample, chosen as reference, is determined externally by wetchemical methods in a subsequent step. An example is ICPOES, but it requires more analyte mass than deposited on a single RDI bar, because the sensitivity is not high enough for these minute masses. Furthermore, the sample material digestion and possible contamination error demanded a new, non-destructive method without structural modification. Since readily available calibration films of similar composition and thickness as the sample do not exist, producing a customized calibration film became necessary. Fittschen et al. $(2006,2010)$ introduced a concept for applying picoliter droplets via an ink-jet printer on different reflector substrates for TXRF. Transforming this approach to the substrates used in SR-XRF by Bukowiecki et al. (2008) gave rise to a procedure of applying standard solutions on thin films with an ink-jet printer. Calibration films were fixed on RDI sample wheels to safeguard that experimental conditions for the SR$\mathrm{XRF}$ analysis are the same.

The use of a Compact Disc-label printer (HP Photosmart D5160), along with the film structure itself ensured optimized adherence of the solution on the substrate because the film is not bent and transported by small brushes as in conventional printers. Clean printer cartridges (type HP 339, completely cleaned by Pelikan Ltd.) with a 15-pl ink drop volume were filled with customized solutions. A precondition for a correct calibration is the similarity of reference and aerosol specimen in terms of homogeneity (grain size and shape), chemical composition and concentration. This would imply using standards with a limited concentration range adapted to the concentration range of the samples. In contrast, a decreasing uncertainty of slope and intercept is obtained for more measurement points in a wider concentration range (Van Grieken, 2002). Therefore, the concentration range was chosen as a compromise between similarity to the sample and reduction of the uncertainty. In this range the relation between fluorescence intensity and mass per printed area is expected to behave linearly.

Two techniques to obtain several increasing coating densities of standard solutions on the substrate were tested: printing one to five times the same amount of solution or printing five areas with different transparency (i.e. "color" saturation in the printer settings). Only the first technique yielded the requested linear increase in mass per coated area. For each of the five coatings pieces of $9 \mathrm{~cm}^{2}$ from the same printing process were analyzed by ICP-OES. The linear relationship of fluorescence intensity (count rate normalized to photon flux and detector dead time) for the reference element $\mathrm{Cd}$ versus the obtained mass per analyzed area ranging from 0.11 to $0.33 \mu \mathrm{g} \mathrm{cm}^{-2}$ is plotted in Fig. 6. The slope of the fitted linear curve of reference element count rate $\left(\Phi_{\mathrm{st}} / t_{\mathrm{c}}\right)$ versus mass per area in $\mu \mathrm{g} \mathrm{cm}^{-2}\left(C_{\mathrm{st}}\right)$ is inserted into the calibration formula introduced below (Eq. 7).

When primary X-rays interact with material, scattering and secondary fluorescence excitation occurs beside primary absorption (Giauque et al., 1979). This implies that the fluorescence intensity of the aerosol sample is not only based on the absolute concentration but can also depend on the total chemical composition (i.e. the matrix seen as sample plus substrate). Owing to the thin sample layer and low mass density of collected particles, the samples are irradiated completely and concentrations are too low to cause secondary $\mathrm{X}$-ray absorption by lighter elements (neglecting the effects of particle size). In the investigated ambient trace element determination, matrix effects were neglected as discussed already by Bukowiecki et al. (2008).

Scattering leads to low peak to background ratios. To keep this scattering as low as possible, it is advisable to use the thinnest substrate possible. However, the thinner the substrate, the more difficult the handling of the film is, so printing inhomogeneities can occur. The chosen substrates represent a compromise between a thin film and satisfactory 


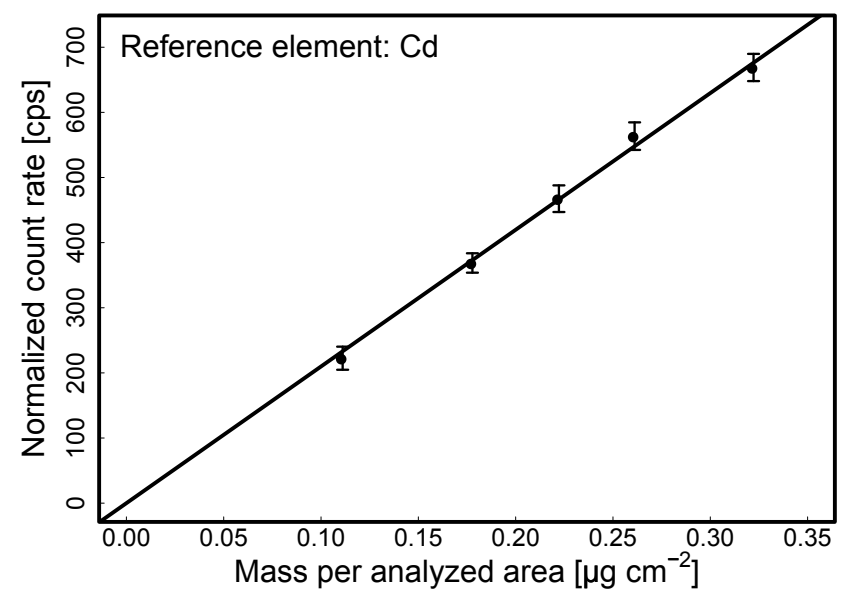

Fig. 6. Fluorescence intensity of reference element Cd: individual data points represent the average count rates (normalized to photon flux and detector dead time) for about 50 spectra of each coating on the calibration film. The absolute mass calibration factor is obtained by the slope of the linear regression (with an intercept of zero) of mean fluorescence count rates in cps versus area concentration in $\mu \mathrm{g} \mathrm{cm}^{-2}$.

printing results. Commercially available films in different thickness were tested: a 100- $\mu \mathrm{m}$ ink jet transparency film (3 M, CG3420), a 100- $\mu$ m PET ink jet film (Folex, BG32.5 RS plus), both coated, a 50- $\mu$ m PET film (Folex, X-131) and a $25-\mu \mathrm{m}$ self adherent polypropylene film, both uncoated. Some films contain interfering elements like Si (adhesive of the self adherent film), S, Al, and $\mathrm{Ca}$, which are also found commonly in ambient aerosol samples. Coated films contain substances for optimal homogeneous drying and the coating density increased linearly when the solution was printed several times on the same area. For the uncoated film activation in a plasma chamber before applying the solution resulted in faster drying and better adhesion to the substrate. For this purpose, an evacuated plasma chamber was filled with oxygen molecules ionized through a high frequency microwave.

Extensive tests of different substrates, solutions and printing processes led to three applicable reference samples, which will be discussed in the following. First, a multielement solution (Merck standard IV, containing Ag, Al, B, $\mathrm{Ba}, \mathrm{Bi}, \mathrm{Ca}, \mathrm{Cd}, \mathrm{Co}, \mathrm{Cr}, \mathrm{Cu}, \mathrm{Fe}, \mathrm{Ga}, \mathrm{In}, \mathrm{K}, \mathrm{Li}, \mathrm{Mg}, \mathrm{Mn}, \mathrm{Na}$, $\mathrm{Ni}, \mathrm{Pb}, \mathrm{Sr}, \mathrm{Tl}, \mathrm{Zn}$ plus single elements: $\mathrm{P}, \mathrm{Rb}, \mathrm{S}, \mathrm{Sb}, \mathrm{Se}$, $\mathrm{Sn}, \mathrm{Ti}, \mathrm{Zr}$ ) was applied on the $100-\mu \mathrm{m}$ PET film with a highresolution printing process $(1200 \mathrm{dpi})$. Next, a self adherent 25- $\mu \mathrm{m}$ PP film was tested. Again, the Merck standard solution IV was the basis and $\mathrm{Rb}$ and Se plasma-standards were added $\left(10 \mathrm{~g} \mathrm{l}^{-1}\right.$ in $\mathrm{HNO}_{3}$ solution) with equal concentration for each element. Through addition of $0.5 \%$ of Triton X-100, a tenside to decrease surface tension, a more homogenous wetting and improved drying speed was achieved. The buffered solution had a $\mathrm{pH}$ of 2 as a compromise between the risk of corrosion of cartridges caused by a low $\mathrm{pH}$

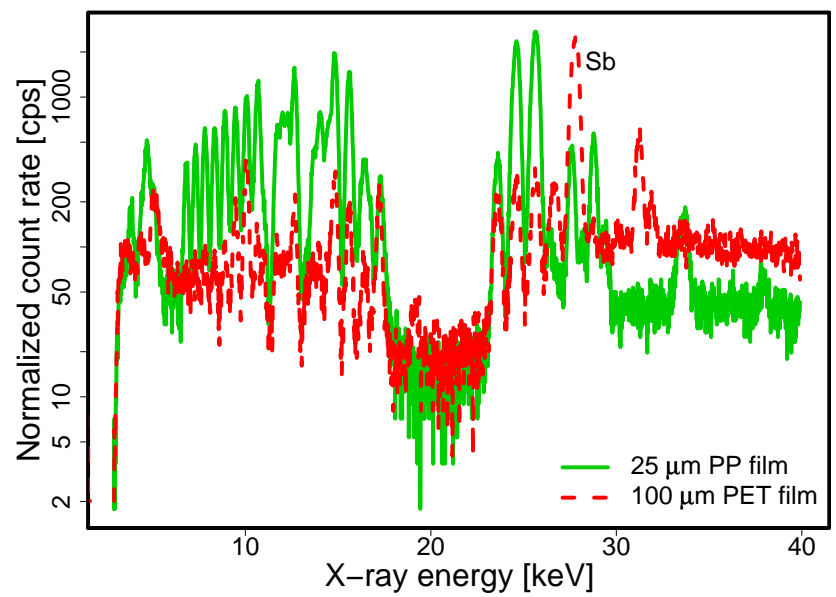

Fig. 7. Comparison of SR-XRF spectra of two different calibration films: count rate of elements in the Merck IV standard solution on a $100-\mu \mathrm{m}$ PET film and the count rate of essentially the same solution on a $25-\mu \mathrm{m}$ PP film. Count rates measured at HASYLAB are normalized to photon flux and detector dead time.

and elemental precipitation/separation caused by a high $\mathrm{pH}$. Count rates of both reference materials (on 100- and 25- $\mu \mathrm{m}$ films) are illustrated in Fig. 7, indicating a much more articulated response curve for the thinner PP film due to reduced scattering. Also, the high Sb peak caused by the $100-\mu \mathrm{m}$ PET substrate vanished for the thinner film. For measurements of the $100-\mu \mathrm{m}$ film the beam exit slit size had to be reduced significantly to avoid saturation of the detector due to high count rates. These count rates were extrapolated according to the determined non-linear relationship between slit size and count rates due to dead time effects for the further analysis. The chosen standard solution led to satisfactory results for the calibration of heavier elements.

However, to calibrate the lighter elements more precisely, a solution containing fewer elements was prepared, avoiding the interference of $\mathrm{L} \alpha$ lines with the $\mathrm{K} \alpha$ lines in focus. Again, clean printer cartridges were filled with a customized solution containing $\mathrm{K}, \mathrm{Ca}$ and Ti standards $\left(10 \mathrm{~g} \mathrm{l}^{-1}\right.$ in $\mathrm{HNO}_{3}$ solution), $\mathrm{Si}$ ( $1 \mathrm{~g} \mathrm{l}^{-1}$ in $\mathrm{HNO}_{3} / \mathrm{HF}$ solution) and $\mathrm{Al}\left(1 \mathrm{~g} \mathrm{l}^{-1}\right.$ in $\mathrm{HNO}_{3}$ solution). Building on the good results obtained before, this solution was applied on the self-adherent $25-\mu \mathrm{m}$ film. The resulting calibration curve is discussed in the next section (Figs. 8 and 9). This reference led to a satisfactory result for lighter elements and showed the high potential of customized calibration solutions for specialized purposes.

\subsection{Relative calibration based on external standardization}

In addition to the absolute mass calibration, a relative calibration is necessary because the fluorescence yield increases 


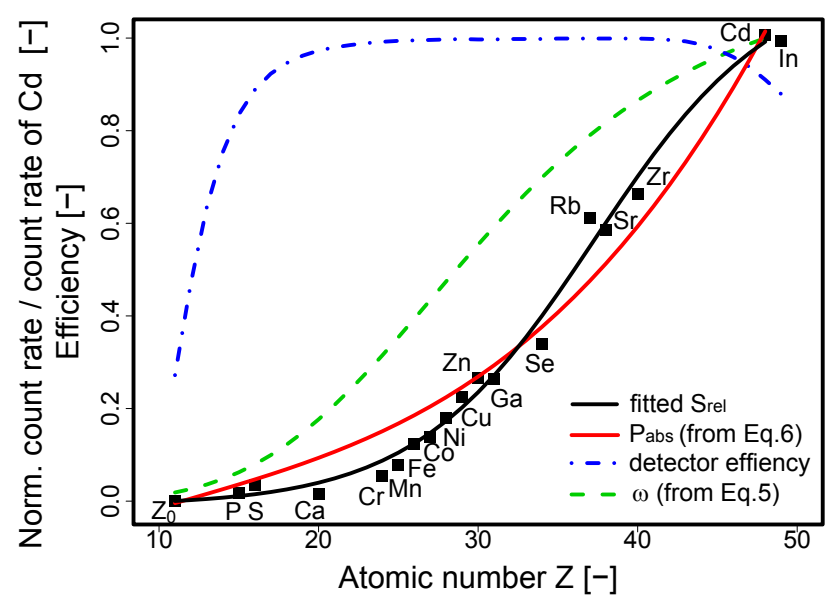

Fig. 8. Relative calibration curve $S_{\text {rel }}$ of $\mathrm{K} \alpha$ lines for measurements at HASYLAB: count rates relative to the count rates of the reference element $\mathrm{Cd}$ are plotted versus atomic number $Z$ with the corresponding fit. Theoretical curves for the fluorescence yield as calculated with Eq. (5), absorbed photon fraction as calculated with Eq. (6) (estimation for experimental conditions taking into account the HASYLAB excitation spectrum with a 8-mm Al absorber) and detector efficiency are shown on the same axis scale. The lower end of the detector efficiency is depicted by $Z_{0}$ in the plot, i.e. the value of $Z$ where the detector efficiency reaches zero.

with increasing atomic number $Z$. The main reason is the Auger effect, a process competing with fluorescence in which the photon is absorbed within the atom and the released energy is emitted through an Auger electron. Absorption of the photon within the atom is most pronounced for lighter atoms, and significantly limits the yield of secondary $\mathrm{X}$-rays from the lighter elements. The fluorescence yield $\omega$ is the relative frequency of photon emission (in competition with the relative frequency of Auger electron emission $\chi$; Bambynek et al., 1972; Burhop et al., 1955). An approximation of $\omega$ is given by:

$\omega=\frac{Z^{4}}{A+Z^{4}}$

with a constant $A=9 \times 10^{5}$ for the K-series and $A=7 \times 10^{7}$ for the L-series. Since Auger electron and fluorescence photon emission are two complementary processes, $\omega+\chi=1$. Because the calibration films (with similar substrate thickness and matrix compared to the samples) contain a series of elements with the same concentration, it is possible to experimentally determine the response curve and calibrate the count rates with a relative factor $\left(S_{\text {rel }}\right)$. The empirically determined $S_{\text {rel }}$ comprises all influences on the effective fluorescence intensity such as theoretical fluorescence yields, mass attenuation caused by sample elements and detector sensitivity. The absorbed photon fraction $P_{\text {abs }}$ was calculated based on the source parameters of the DORIS III storage ring plus the 8-mm Al absorber inserted into the beam path (Sánchez

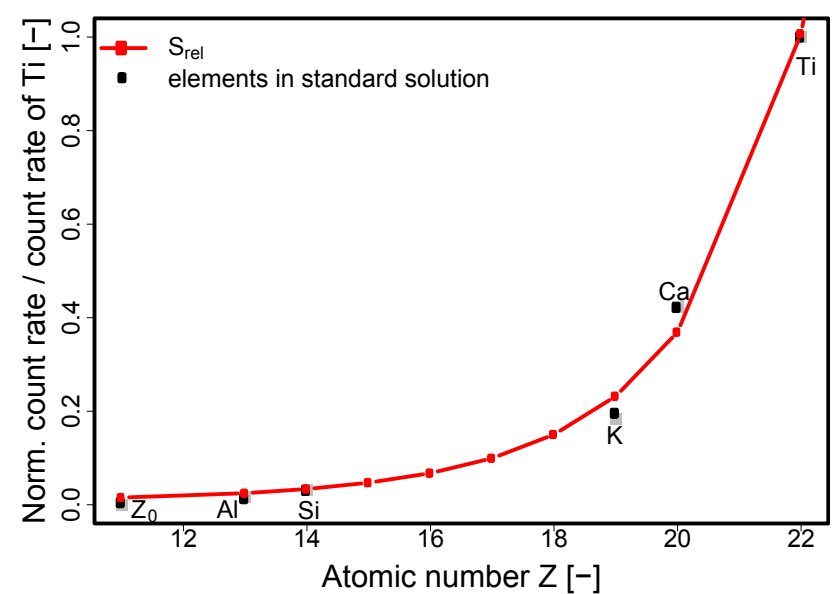

Fig. 9. Relative calibration curve $S_{\text {rel }}$ of K $\alpha$ lines for measurements at SLS: count rates are normalized to detector dead time and plotted relative to the count rate of Ti, blank values are always subtracted. An exponential fit was applied to the data and shows the extrapolated relative calibration curve $S_{\text {rel }}$ for all elements in the sample. The lower end of the detector efficiency is depicted by $Z_{0}$ in the plot.

del Río et al., 2004) and mass attenuation coefficients of Xrays for chosen elements in the sample (Berger et al., 2007):

$P_{\mathrm{abs}}=\sum_{E_{i}<E\left(\Phi_{0}\right)}\left(\Phi_{0} x_{\mathrm{s}}-\frac{\Phi_{0}}{\mu \rho}\left(1-e^{\left(-\mu \rho x_{\mathrm{s}}\right)}\right)\right)$

In this approximation for infinite thin films, the contributions of absorption caused by the relevant polychromatic photon intensities $\Phi_{0}$ for typical elements were summed up. Other variables in the equation are the sample thickness $x_{\mathrm{s}}$, the total absorption mass attenuation coefficient $\mu$ and the material density $\rho$. The calculated absorbed photon fraction reflects the overall trend of the empirical curve.

All three calculated curves were added to Fig. 8 showing the empirical relative calibration curve of $\mathrm{K} \alpha$ lines for measurements at HASYLAB. A sigmoidal or exponential fit to the data points turned out to provide the best extrapolation of the relative curve for those sample elements that are not contained in the calibration solution. The energy where the detector efficiency drops to zero $\left(Z_{0}\right)$ is included as the lower limit of the fit. Since Cd was chosen as reference element in the absolute mass calibration, the count rates for $S_{\text {rel }}$ in Fig. 8 are normalized to the count rate of $\mathrm{Cd}$.

Figure 9 displays the relative calibration curve $S_{\text {rel }}$ obtained by analyzing the calibration reference customized for lighter elements with SR-XRF at the SLS. Here, a similar curve to previous experiments was found and through the fit to data all elements in the sample can be analyzed. 
Coating homogeneity, reproducibility of printed areas and stability of printed surface are challenges in the printing process. Scanning electron microscope (SEM) images from printed calibration and blank films revealed a sufficiently good homogeneity of applied droplets. The presented results show that customized calibration films for different experimental SR-XRF conditions can be produced with the ink-jet printer method.

\subsection{Calibration formula}

Spectra were fitted with the WinAxil software package (Canberra Inc.; Van Espen et al., 1986; Vekemans et al., 2004) using a least squares fitting algorithm with a Bremsstrahlung background. Although the Bremsstrahlung background originally has its source in the description of electron induced $\mathrm{X}$-rays, where retardation of the electrons is almost completely responsible for the continuum, this model was able to reconstruct the background curvature best (visual inspection). Spectral counts obtained by WinAxil are calibrated with the absolute mass calibration factor $C_{\mathrm{st}} / \Phi_{\mathrm{st}}$ and the relative calibration factor $S_{\text {rel }}$. The ambient concentration $C$ of one element is deduced from the fluorescence intensity $\Phi$ by the following calibration formula:

$C=\frac{\Phi C_{\mathrm{st}} A_{i} t_{\mathrm{c}}}{\Phi_{\mathrm{st}} S_{\mathrm{rel}} A_{\mathrm{c}} t_{\mathrm{m}}} \frac{1}{t_{\mathrm{RDI}} Q_{\mathrm{RDI}}} \frac{100}{100-t_{\mathrm{d}}} \frac{I_{\mathrm{m}}}{I_{\mathrm{D}}}$

with the RDI bar area $\left(A_{10}=15.2 \mathrm{~mm}^{2}, A_{2.5}=6.8 \mathrm{~mm}^{2}\right.$ and $A_{1}=3.0 \mathrm{~mm}^{2}$ ), the total calibration film area analyzed by ICP-OES $\left(A_{\mathrm{c}}=9 \mathrm{~cm}^{2}\right)$, the respective irradiation times for aerosol $\left(t_{\mathrm{m}}\right)$ and calibration spectra $\left(t_{\mathrm{c}}\right)$, the RDI sampling interval $\left(t_{\mathrm{RDI}}\right)$, the RDI flow $\left(Q_{\mathrm{RDI}}\right)$, the dead time caused in the detector $\left(t_{\mathrm{d}}\right)$, the actual beam current $\left(I_{\mathrm{D}}\right)$ and the maximum beam current directly after injection $\left(I_{\mathrm{m}}\right)$. The last term $I_{\mathrm{m}} / I_{\mathrm{D}}$ is only applied to measurements performed at HASY$\mathrm{LAB}$, where the raw count rates have to be normalized to the photon flux. No correction is necessary for measurements at SLS because of a constant beam current due to top-up injection. As mentioned before this calibration technique is only applicable for references with similar elemental matrix and similar film thickness.

Measurement uncertainties were calculated with uncertainty propagation of the three terms in Eq. (7) containing an uncertainty. The extrapolation from the rather small-sized beam spot to the RDI bar area $\left(A_{\text {beam }} \approx 1 \%\right.$ of total area $\left.A_{i}\right)$ adds to the total measurement uncertainty with a contribution of $20 \%$ of the area. Further uncertainty is introduced by possible slight variations in the RDI flow, which is estimated to contribute a relative uncertainty of $5 \%$. The third term is the uncertainty obtained by the linear regression for the calculation of the absolute mass calibration factor.

Minimal detection limits (MDL) were determined as a means for the qualitative evaluation of every individual data point. Only elements exceeding the MDL with $>50 \%$ of

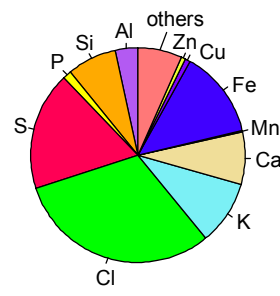

PM10-2.5

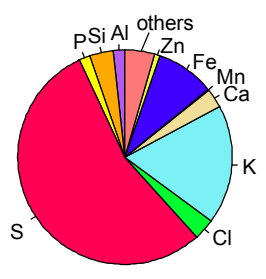

PM2.5-1

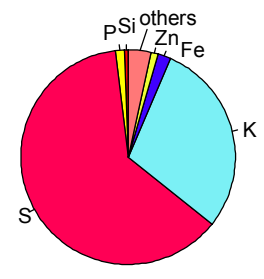

PM1-0.1
Fig. 10. Pie charts for relative contributions of measured elements in the three size ranges $\left(\mathrm{PM}_{10-2.5}, \mathrm{PM}_{2.5-1}\right.$ and $\left.\mathrm{PM}_{1-0.1}\right)$ from the winter campaign in Zürich Kaserne obtained by RDI-SR-XRF trace element analysis.

values remained in the final data set. These detection limits are calculated as follows:

$\mathrm{MDL}=\frac{C_{\mathrm{st}} A_{i}}{\Phi_{\mathrm{st}} S_{\mathrm{rel}} A_{\mathrm{c}} t_{\mathrm{RDI}} Q_{\mathrm{RDI}}} 3 \cdot \sqrt{\frac{\Phi_{B}}{t_{\mathrm{m}}}}$

with $\Phi_{B}$ being the elemental continuum counts obtained by fitting a Bremsstrahlung background. Thus, a longer counting time improves the MDL for a fixed setup.

\section{Discussion and selected results}

The segregation into three size ranges in the RDI enables a more detailed interpretation of the relative elemental composition. Quantitative ambient aerosol measurements can be obtained through application of the calibration for the SRXRF method described in Sect. 3. To support and consolidate these two findings, exemplary results are presented, while the full data set will be presented in an upcoming paper. The RDI was deployed in a field campaign at Zürich Kaserne, Switzerland for time and size resolved trace element sampling from 28 November 2008 to 5 January 2009 (with a short break from 26 to 28 December) and a time resolution of $2 \mathrm{~h}$.

The relative elemental composition for the three size ranges is illustrated in Fig. 10. Note that for these pie charts, the period from 31 December 2008 15:00 LT to 1 January 2009 05:00 LT is excluded to not distort the picture through unusually high emissions of some elements - e.g. S, $\mathrm{K}, \mathrm{Ti}, \mathrm{Cu}, \mathrm{Sr}, \mathrm{Ba}$ (and $\mathrm{Sb}$ ) - during the fireworks at New Year's Eve. Nonetheless, sulfur and potassium account for the highest contributions in the fine size range. Secondary sulfate and biomass combustion emissions are assumed to contribute primarily to the high sulfur concentration. Ammonium sulfate is formed by conversion of $\mathrm{SO}_{2}$ to sulfuric acid via either heterogeneous reactions in droplets (with ozone, $\mathrm{NO}_{2}, \mathrm{H}_{2} \mathrm{O}_{2}$ ) or photochemically via $\mathrm{OH}$ radicals (Seinfeld, 1998), followed by neutralization by ammonia. Fine potassium also originates mainly from combustion processes. In the coarse size range, $\mathrm{Cl}$ (presumably from de-icing salt) and 
Fe contribute the highest amounts to the mass. This gain in information through the size resolution of the RDI enhances the potential of source apportionment studies significantly (Han et al., 2005; Ondov et al., 2006; Karanasiou et al., 2009).

The trace element percentage of the average $\mathrm{PM}_{10}$ mass concentration during the campaign is obtained by the sum of $\mathrm{PM}_{10-2.5}+\mathrm{PM}_{2.5-1}+\mathrm{PM}_{1-0.1}$, and similarly for $\mathrm{PM}_{2.5}$. The average mass contributed by all detected elements (Al, $\mathrm{Si}, \mathrm{P}, \mathrm{S}, \mathrm{Cl}, \mathrm{K}, \mathrm{Ca}, \mathrm{Ti}, \mathrm{Cr}, \mathrm{Mn}, \mathrm{Fe}, \mathrm{Co}, \mathrm{Ni}, \mathrm{Cu}, \mathrm{Zn}, \mathrm{Sr}, \mathrm{Zr}$, $\mathrm{Mo}, \mathrm{Cd}, \mathrm{Sn}, \mathrm{Sb}, \mathrm{Ba}$ and $\mathrm{Pb}$, not extrapolated to the corresponding oxides) to the average $\mathrm{PM}_{10}$ mass concentration of $24.6 \mu \mathrm{g} \mathrm{m}^{-3}$ quasi-continuously monitored (every $10 \mathrm{~min}$ ) by a tapered element oscillating microbalance (TEOM 8500) amounts to $4.6 \mu \mathrm{g} \mathrm{m}^{-3}$, thus to about $20 \%$. The average mass concentration of $\mathrm{PM}_{2.5}$ was retrieved from daily filters of high-volume samplers (Digitel AG, Aerosol Sampler DHA80 ) to be $21 \mu \mathrm{g} \mathrm{m}^{-3}$ and detected elements summed up to $3 \mu \mathrm{g} \mathrm{m}^{-3}$, corresponding to about $15 \%$ of the total $\mathrm{PM}_{2.5}$ mass concentration. Again, the period during New Year's Eve is excluded, for more details see Table 1 in the Supplement.

In order to validate the obtained mass concentrations, results from RDI measurements were compared to independent 24-h trace element filter data from the same campaign. Two high-volume samplers (Digitel AG, DHA-80) with PM $_{1}$ and $\mathrm{PM}_{10}$ inlets were used to collect 24-h samples on 1, 3, 5, 7, 9, 11, 13, 15 and 17 December 2008. A fraction of the quartz micro-fiber filter was acid digested and subsequently analyzed by ICP-OES and ICP-MS for the determination of major and minor elements (see details of the method in Querol et al., 2008). A comparison of $\mathrm{PM}_{10}$ data from the filter and the RDI analysis for characteristic elements $(\mathrm{S}, \mathrm{K}, \mathrm{Fe}, \mathrm{Cu}$, $\mathrm{Sn}$ and $\mathrm{Sb}$ ) is shown in Fig. 11. $\mathrm{PM}_{1}$ data did not reach the detection limit for a number of elements. Nonetheless, averaged concentrations of elements detected by both methods for days of simultaneous measurements compared very well: the average concentration of $\mathrm{PM}_{1}$ filter data was equal to $0.64 \mu \mathrm{g} \mathrm{m}^{-3}$ while the average concentration of $\mathrm{PM}_{1-0.1}$ RDI data summed up to $0.68 \mu \mathrm{g} \mathrm{m}^{-3}$ (this comparison includes the following elements: $\mathrm{Al}, \mathrm{P}, \mathrm{S}, \mathrm{K}, \mathrm{Ca}, \mathrm{Ti}, \mathrm{V}, \mathrm{Cr}$, $\mathrm{Mn}, \mathrm{Fe}, \mathrm{Co}, \mathrm{Ni}, \mathrm{Cu}, \mathrm{Zn}, \mathrm{Rb}, \mathrm{Sr}, \mathrm{Zr}, \mathrm{Cd}, \mathrm{Sn}, \mathrm{Sb}, \mathrm{Ba}$ and $\mathrm{Pb}$ ). Average concentrations of $\mathrm{PM}_{10}$ filter data amounted to $2.7 \mu \mathrm{g} \mathrm{m}^{-3}$ and the average concentration of $\mathrm{PM}_{10-0.1} \mathrm{RDI}$ data was equal to $2.55 \mu \mathrm{g} \mathrm{m}^{-3}$, including the same elements as for $\mathrm{PM}_{1}$ as well as $\mathrm{Cl}$ and Mo. For more details see Table 1 in the Supplement. RDI data were binned into 24-h intervals by calculating the mean of 12 data points, and all three RDI stages were summed up for the comparison to $\mathrm{PM}_{10}$. Time series for the chosen elements are visualized in Fig. 11. Measurement uncertainty bars in Fig. 11 are calculated as described above for RDI data and propagated for the calculation of the mean value, while the uncertainty for filter data was calculated following the method of Escrig et al. (2009). The variability of the RDI data is indicated through the 2-h

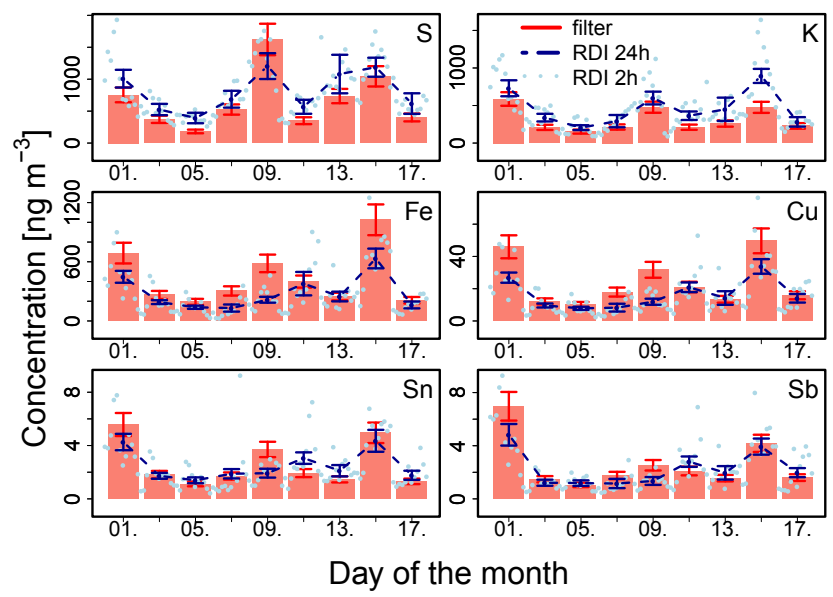

Fig. 11. Comparison of time series of 2-h RDI values to daily highvolume filter samples. $\mathrm{PM}_{10}$ filter values are compared to the sum of all RDI stages from Zürich winter campaign for typical elements $\mathrm{S}, \mathrm{K}, \mathrm{Fe}, \mathrm{Cu}, \mathrm{Sn}$ and $\mathrm{Sb}$. The 2-h RDI data are shown in light blue, the 12 corresponding RDI values binned to 24 -h values are shown in dark blue and the 24-h filter values are shown as red bar plots. Filter samples were taken every other day on $1,3,5,7,9,11,13$, 15 and 17 December 2008.

values in the plot, corresponding to a standard deviation $\sigma$ in the order of $30-40 \%$. Pearson correlation coefficients lie in the order of 0.9 , if one outlier data point is excluded, see also Fig. 1 in the Supplement.

Some days (e.g. 9 December) show a higher variability than others which may be due to increased sample inhomogeneity or other unknown experimental issues. The sample inhomogeneity is a critical issue if only a fraction of the total sample area is analyzed using focused SR-XRF beams. The low number of sampled particles in the RDI (estimated to be around 10000 particles/analyzed area for stage 1 and 100 particles/analyzed area for stage 10, see Bukowiecki et al., 2008, 2009) raises the question of sufficient uniformity of the deposited material. In both beam line setups the respective possible maximum beam sizes were chosen. Due to the constraints given by the beamline optics as well as the geometry of the sample holder, it was never possible to match the beam cross section exactly to the RDI bars. In earlier work (Bukowiecki et al., 2009), specifically addressing the uniformity, a 2-D-high resolution scan was performed with a considerably smaller micro-focus beam (beam size $4 \mu \mathrm{m}^{2}$, step width $7 \mu \mathrm{m}$ ) at the LUCIA beamline at SLS, PSI. There, it could be seen that some elements deposit in distinct spots. For a 1-h stage 10 RDI sample of urban ambient air, an average Fe particle-to-particle distance of about $70 \mu \mathrm{m}$ was estimated, corresponding to a particle area density of $213 \mathrm{Fe}$-containing particles $\mathrm{mm}^{-2}$. The FWHM of the area of $\mathrm{Fe}$-containing particles on the film was found to be $1.4 \mathrm{~mm}$, which is reasonably close to the nozzle width and thus RDI bar width of $1.52 \mathrm{~mm}$. However, no sharp 
edges were found. For stage 2.5 a Fe particle-to-particle distance of about 30-40 $\mu \mathrm{m}$ and an overall particle-to-particle distance of less than $2 \mu \mathrm{m}$ were estimated. These values lie within the dimensions of the beam sizes $(100 \times 200 \mu \mathrm{m}$ and $70 \times 140 \mu \mathrm{m})$.

Furthermore, TEM images were taken in that same study showing the uniformity of sampled particles on the film. The total number of particles in the coarse size range was found to be around 800 particles $\mathrm{mm}^{-2}$ for a 1 -h aerosol sample. The density of particles is lowest for the coarse size fraction and increasingly higher for the smaller size ranges. On the basis of this information, it is assumed that the chosen beam sizes for analysis at the SLS X05DA beam line and the HASYLAB $\mathrm{L}$ beam line allow for an extrapolation from the measured to total sample area if an adequate uncertainty estimate is assigned to the values. As mentioned above, the RDI bar area contributes an error of $\pm 20 \%$ to the uncertainty calculation.

In the case of the filter analysis, outliers due to sample inhomogeneity are rather improbable since the percentage of analyzed area from total sample area amounts to $12.5 \%$ ( $1 / 8$ of the filter) and is thus significantly larger than for the RDI analysis. Since inhomogeneities in the distribution of the material on the filters are a function of the distance to the center, portions of the filter were taken like pieces of a round pie to avoid this influence (Brown et al., 2009).

But, since 12 RDI values are averaged to be compared to one filter value, it is difficult to find an explanation for the discrepancy in just one of the two methods. Also, correlations of RDI values versus filter values show no clear trend towards a general over- or under-estimation by the RDI analysis and thus it is assumed that deviations lie within the uncertainties of both methods and atmospheric variability.

The gain in information obtained by a higher time resolution, which can lead to the identification of diurnal variations, is a major advantage of the RDI method. Eventually, the overall comparison of 24-h concentration values shows reasonable agreement within the limits of both methods and therefore confirms the applicability of the presented calibration methodology.

\section{Conclusions}

The cutoff diameters of a rotating drum impactor were measured through quasi monodisperse DEHS particles and polydisperse $\mathrm{NaCl}$ particles to consolidate previous studies carried out in laboratory room air. Results show good agreement with theoretical values and confirm the validity of the earlier experiment (Bukowiecki et al., 2009). However, the cutoff sharpness for the analyzed impactor is broader than that found for other cascade impactors.

The developed calibration method for SR-XRF count rates to ambient concentrations properly matched the requirements (similar elemental composition, particle size, sample homogeneity and substrate thickness for ambient aerosol analysis on PP films) and provided an external, reusable reference material for the presented studies. The aim of obtaining consistent data sets from different experimental sessions for subsequent source apportionment studies was reached. The procedure is advantageous over already existing standards as the elemental composition and the thickness of the substrate is comparable to the sample composition and the film used for sampling. However, when using a calibration film that does not contain sufficient elements in the region of interest, adaptation to additional data, such as filter values may be necessary. Printing standard solutions on a simple transparency film with a conventional Compact Disk-label printer forms an easy to handle approach for both relative and absolute mass calibration. Averaging a series of spectra leads to a satisfactory result, although the printing homogeneity might be improved in the future by using a professional large-scale printer. While the substrate film thickness was appropriate in the presented case, a professional printer with the possibility to fix the film through electrostatic adhesion or a vacuum sample holder could lead to the use of a thinner film where lower background effects are expected.

The comparison of high time resolved and size-segregated RDI data to 24-h filter data shows generally good agreement although outliers due to the variability in both methods were observed. Despite the need for access to a synchrotron facility to conduct SR-XRF analysis for high time resolution trace element data, the results demonstrate that the gain in information compared to conventional low time resolution wet-chemical evaluation justifies these efforts. High time resolution data is expected to enable a better identification of sources because daily patterns such as peak-traffic hours and other day-night differences in anthropogenic activities can be observed. This will be exploited for the current data set to perform source apportionment with positive matrix factorization (PMF) in an upcoming paper.

\section{Supplementary material related to this article is available online at: http://www.atmos-meas-tech.net/3/1473/2010/ amt-3-1473-2010-supplement.pdf.}

Acknowledgements. The presented work is partly funded by the Swiss Federal Roads Office (ASTRA), the Swiss Federal Office for the Environment (BAFU) and a post-doc contract sponsored by the Spanish Ministry of Science and Innovation (MICINN). Parts of the work were performed at the Swiss Light Source, Paul Scherrer Institut, Villigen, Switzerland. We thank Andreas Jaggi for technical support at the beamline X05DA. Portions of this research were carried out at the light source facility DORIS III at HASYLAB/DESY. DESY is a member of the Helmholtz Association (HGF). We thank Ferenc Hegedüs for his valuable input for the production of calibration standards and Marc Stammbach, Pelikan Ltd. for providing empty printer cartridges. Most of the data analysis was performed with the $\mathrm{R}$ software package for statistical computing (R Development Core Team , 2008).

Edited by: J.-P. Putaud 


\section{References}

Bambynek, W., Crasemann, B., Fink, R. W., Freund, H. U., Mark, H., Swift, C. D., Price, R. E., and Venugopala Rao, P.: X-ray fluorescence yields, Auger, and Coster-Kronig transition probabilities, Rev. Mod. Phys., 44, 716-813, 1972.

Berger, M. J., Hubbell, J. H., Seltzer, S. M., Chang, J., Coursey, J. S., Sukumar, R., and Zucker, D. S.: XCOM: Photon Cross Sections Database, NIST Standard Reference Database 8 (XGAM), 2007.

Berner, A. and Lurzer, C.: Mass size distributions of traffic aerosols at Vienna, J. Phys. Chem., 84, 2079-2083, 1980.

Bukowiecki, N., Hill, M., Gehrig, R., Zwicky, C. N., Lienemann, P., Hegedüs, F., Falkenberg, G., Weingartner, E., and Baltensperger, U.: Trace metals in ambient air: hourly sizesegregated mass concentrations determined by synchrotron-XRF, Environ. Sci. Technol., 39, 5754-5762, 2005.

Bukowiecki, N., Lienemann, P., Zwicky, C. N., Furger, M., Richard, A., Falkenberg, G., Rickers, K., Grolimund, D., Borca, C., Hill, M., Gehrig, R., and Baltensperger, U.: X-ray fluorescence spectrometry for high throughput analysis of atmospheric aerosol samples: the benefits of synchrotron X-rays, Spectrochim. Acta B, 63, 929-938, 2008.

Bukowiecki, N., Richard, A., Furger, M., Weingartner, E., Aguirre, M., Huthwelker, T., Lienemann, P., Gehrig, R., and Baltensperger, U.: Deposition uniformity and particle size distribution of ambient aerosol collected with a rotating drum impactor, Aerosol Sci. Tech., 43(9), 891-901, 2009.

Burhop, E. H. S.: Le rendement de fluorescence, J. Phys. Radium, 16, 625-629, 1955.

Brown, R. J. C., Jarvus, K. E., Disch, B. A., Goddard, S. L., and Brown, A. S.: Spatial inhomogeneity of metals in particulate matter on ambient air filters determined by LA-ICP-MS and comparison with acid digestion ICP-MS, J. Environ. Monitor., 11, 2022-2029, 2009.

Cahill, T. A., Goodart, C., Nelson, J. W., Eldred, R. A., Nasstrom, J. S., and Feeney, P. J.: Design and evaluation of the DRUM impactor, Particulate Science and Technology, Hemisphere Publications, Washington, DC, Proceedings of International Symposium on Particulate and Multiphase Processes, 1985.

Cliff, S. S., Cahill, T. A., Jimenez-Cruz, M., and Perry, K. D.: Synchrotron X-Ray fluorescence analysis of atmospheric aerosols using ALS beamline 10.3.1: application to atmospheric pollution evolution and transport, Abstr. Pap. Am. Chem. S., 225, 837, 2003.

D’Alessandro, A., Lucarelli, F., Mando, P. A., Marcazzan, G., Nava, S., Prati, P., Valli, G., Vecchi, R., and Zucchiatti, A.: Hourly elemental composition and sources identification of fine and coarse $\mathrm{PM}_{10}$ particulate matter in four Italian towns, J. Aerosol Sci., 34, 243-259, 2003.

Escrig, A., Monfort, E., Celades, I., Querol, X., Amato, F., Minguillón, M. C., and Hopke, P. K.: Application of optimally scaled target factor analysis for assessing source contribution of ambient $\mathrm{PM}_{10}$, J. Air Waste Manage., 59(11), 1296-1307, 2009.

Fittschen, U., Hauschild, S., Amberger, M. A., Lammel, G., Streli, C., Förster, S., Wobrauschek, P., Jokubonis, C., Pepponi, G., Falkenberg, G., and Broekaert, J. A. C.: A new technique for the deposition of standard solutions in total reflection $\mathrm{X}$-ray fluorescence spectrometry (TXRF) using pico-droplets generated by inkjet printers and its applicability for aerosol analysis with SR-TXRF, Spectrochim. Acta B, 61, 1098-1104, 2006.

Fittschen, U. and Havrilla, G. J.: Picoliter droplet deposition using a prototype picoliter pipette: control parameters and application in micro X-ray fluorescence, Anal. Chem., 82, 297-306, 2010.

Flechsig, U., Jaggi, A., Spielmann, S., Padmore, H. A., and MacDowell, A. A.: The optics beamline at the Swiss Light Source, Nucl. Instrum. Meth. A, 609, 281-285, 2009.

Giauque, R., Garrett, R. B., and Goda, L. Y.: Determination of trace elements in light element matrices by $\mathrm{X}$-ray fluorescence spectrometry with incoherent scattered radiation as an internal standard, Anal. Chem., 51, 511-516, 1979.

Han, J. S., Moon, K. J., Ryu, S. Y., Kim, Y. J., and Perry, K. D.: Source estimation of anthropogenic aerosols collected by a DRUM sampler during spring of 2002 at Gosan, Korea, Atmos. Environ., 39, 3113-3125, 2005.

Hering, S. V. and Friedlander, S. K.: Design and evaluation of a new low-pressure impactor, Environ. Sci. Technol., 13, 184188, 1979.

Hinds, C. W.: Aerosol Technology, Properties, Behavior, and Measurement of Airborne Particles, John Wiley and Sons, New York, 1982.

Karanasiou, A. A., Siskos, P. A., and Eleftheriadis, K.: Assessment of source apportionment by positive matrix factorization analysis on fine and coarse urban aerosol size fractions, Atmos. Environ., 43, 3385-3395, 2009.

Kwon, S. B., Lim, K. S., Jung, J. S., Bae, G. N., and Lee, K. W.: Design and calibration of a 5-stage cascade impactor (K-JIST Cascade Impactor), J. Aerosol Sci., 34, 289-300, 2003.

Lundgren, D.: An aerosol sampler for determination of particulate concentration as a function of size and time, JAPCA J. Air Waste Ma., 17, 225-229, 1967.

Marjamäki, M., Keskinen, J., Chen, D.-R., and Pui, D. Y. H.: Performance evaluation of the electrical low-pressure impactor (ELPI), J. Aerosol Sci., 31(2), 249-261, 2000.

Marple, V., Rubow, K. L., and Behm, S. M.: A microorifice uniform deposit impactor (MOUDI): description, calibration, and use, Aerosol Sci. Tech., 14, 434-446, 1991.

Marple, V.: History of impactors - the first 110 years, Aerosol Sci. Tech., 38, 247-292, 2004.

Ondov, J. M., Buckley, T. J., Hopke, P. K., Ogulei, D., Parlange, M. B., Rogge, W. F., Squibb, K. S., Johnston, M. V., and Wexler, A. S.: Baltimore Supersite: highly time- and sizeresolved concentrations of urban $\mathrm{PM}_{2.5}$ and its constituents for resolution of sources and immune responses, Atmos. Environ., 40, 224-237, 2006.

Querol, X., Pey, J., Minguillón, M. C., Pérez, N., Alastuey, A., Viana, M., Moreno, T., Bernabé, R. M., Blanco, S., Cárdenas, B., Vega, E., Sosa, G., Escalona, S., Ruiz, H., and Artíñano, B.: PM speciation and sources in Mexico during the MILAGRO-2006 Campaign, Atmos. Chem. Phys., 8, 111-128, doi:10.5194/acp8-111-2008, 2008.

R Development Core Team: R: A language and environment for statistical computing. R Foundation for Statistical Computing, http://www.R-project.org, last access: 15 May 2010, Vienna, Austria, ISBN 3-900051-07-0, 2008.

Raabe, O. G., Braaten, D. A., Axelbaum, R. L., Teague, S. V., and Cahill, T. A.: Calibration studies of the DRUM impactor, J. Aerosol Sci., 10(2), 183-195, 1988. 
Rousseau, R., Willis, J. P., and Duncan, A. R.: Practical XRF calibration procedures for major and trace elements, X-ray Spectrom., 25, 179-189, 1996.

Sánchez del Río, M. and Dejus, R. J.: XOP 2.1: a new version of the X-ray optics software toolkit, in: Synchrotron Radiation Instrumentation: Eighth International Conference, edited by: Warwick, T., Arthur, J., Padmore, H. A., and Stohr, J., American Institute of Physics, 784-787, 2004.

Seinfeld, J. H. and Pandis, S. N.: Atmospheric Chemistry and Physics: From Air Pollution to Climate Change, John Wiley and Sons, New York, 1998.
Vekemans, B., Vincze, L., Brenker, F. E., and Adams, F.: Processing of three-dimensional microscopic X-ray fluorescence data, J. Anal. Atom. Spectrom., 19, 1302-1308, 2004.

Van Espen, P., Janssens, K., and Nobels, J.: AXIL-PC, software for the analysis of complex X-ray spectra, Chemometr. Intell. Lab., 1, 109-114, 1986.

Van Grieken, R. E. and Markowicz, A. A.: Handbook of X-ray Spectrometry, Marcel Dekker, Inc., New York, 2002. 